\title{
Modeling of End-Space Convection Heat-Transfer for Internal and External Rotor PMSMs with Fractional-Slot Concentrated Windings
}

\author{
Aitor Tovar-Barranco, Amaia López-de-Heredia, Irma Villar, Member, IEEE, \\ and Fernando Briz, Senior Member, IEEE
}

\begin{abstract}
Modeling of convection heat-transfer at the end-windings for thermal networks using lumpedparameters has been widely discussed in the literature. Unfortunately, the resulting coefficients are highly influenced by the end-winding shape, the area in the vicinity of the end-windings, the cooling method of this region (if any), as well by the size and power of the machine. This makes extremely difficult for the designer to choose a suitable coefficient for the thermal analysis during the design stage of an electric motor. A methodology to obtain the end-windings convection heat-transfer coefficients for fractional-slot concentrated winding permanent-magnet synchronous motors is proposed in this paper. Machine designs with both internal and external rotors will be considered. The experimental tests required for the model characterization are described in detail. General expressions of the convection heat-transfer coefficients between the end-windings and the housing end-caps are proposed for both internal and external rotor designs. Differences observed with results reported in the literature are also discussed.
\end{abstract}

Index Terms-Permanent-magnet machines, fractionalslot concentrated winding, thermal analysis, lumpedparameter thermal network, end-space convection heattransfer, end-winding cooling.

\section{INTRODUCTION}

$\mathbf{P}$ ERMANENT-MAGNET synchronous machines (PMSMs) with fractional-slot concentrated windings (FSCW) have already been employed in electric and hybrid propulsion vehicles due to their high torque density, high efficiency, low torque ripple, good flux-weakening capability and inherent fault-tolerance [1]-[3]. On the other hand, external rotor designs can be beneficial for in-wheel motor topologies for electric vehicles [4], [5] and modern lightweight vehicles, such as electric bicycles [6], [7].

Project co-financed by the Basque Government and the EU through the European Regional Development Fund 2014-2020 (FEDER), under project GANICS (ELKARTEK, KK-2017/00050).

A. Tovar-Barranco, A. López-de-Heredia and I. Villar are with the Power Electronics Area, Ikerlan Technology Research Centre, Basque Research and Technology Alliance (BRTA). Arrasate-Mondragón 20500, Spain (e-mail: atovar@ikerlan.es; alopezheredia@ikerlan.es; ivillar@ikerlan.es)

F. Briz is with the Department of Electrical, Electronics, Computers and Systems Engineering, University of Oviedo. Gijón 33204, Spain (e-mail: fernando@isa.uniovi.es).
Thermal analysis is a mandatory during the design process of an electric machine, especially in applications in which the machine is expected to operate at its temperature limits. A precise understanding of the heat-transfer phenomenon within the electric motor will enable performance improvements, volume reduction, etc. Traditionally the design was based on generic equations in which, for a given air-gap volume, the designer defined electric and magnetic constraints based on previous experiences [8]. This often resulted in large errors in the estimation of the thermal behavior of the machine. Advances in computers over the last years have resulted in powerful tools for the thermal analysis of electric machines. Available methods can be grouped into two major categories: analytical lumped-parameter thermal networks (LPTN) and numerical methods. The last group can be divided into finiteelement methods (FEM) and computational fluid dynamics (CFD). An exhaustive review of both approaches can be found in [9].

Choosing between LPTN and numerical methods involve both computational requirements and accuracy aspects. Analytical LPTN models are relatively simple, enabling therefore the thermal characterization of multiple design options [10], [11]. On the contrary, numerical methods can provide much more detailed results, but its use must be limited to a few design options due to the increased computational (and therefore time) requirements [3], [12]-[16]. A mix between both approaches is efficiently implemented in [17], where A LPTN model of the complete machine is complemented with specific CFD/FEM simulations. Due to numerical methods being high time-consuming, even with advancement in computers, they are not the preferred solution during initial design stages of electric motors. In this context, this paper is focused on the accuracy improvement of LPTN methods.

A pioneering work describing the detailed LPTN model of the whole electric machine was published by Mellor in 1991 [10]. The method used thermal resistances derived from purely geometric information, thermal properties of the materials and heat-transfer coefficients. Thermal resistances modelled the three physical heat-transfer mechanisms between the different elements of the machine: conduction, convection and radiation. The accuracy of the method analysis is highly dependent on the quality of the models used for characterizing these 
phenomena. Following this pioneering work, there has been an intensive research aimed to improve the accuracy of the models structure and parameters, a thorough review can be found in [18]. Inverse thermal modelling techniques have been widely use for the identification of lumped parameters of thermal models [19] and accuracy improvements of FEM computations [20]. However, despite of these efforts, some heattransfer coefficients still suffer from significant uncertainty. More specifically, modeling convection at the end-windings remains to be properly solved, due to the difficulties intrinsic to geometries involved as well as to uncertainties modeling the air flow in the surroundings.

End-windings are usually the hottest spots in an electric machine. High performance electric motors may employ specific cooling methods for the end-windings [21], [22]. For the case of industrial induction machines, fins attached to the rotor short-circuit rings (usually known as wafters) have been traditionally employed in totally enclosed designs to boost the airflow within the end-space region [13], [14]. This reduces the risk of irreversible damage of the insulation of the copper, but this is at the expense of increasing the windage losses. Several authors have addressed characterization of the heattransfer within the end-space region. Methods reported in [13]-[16] are based on numerical approaches being therefore beyond the scope of this paper. Earlier, Schubert [23] proposed an empirical correlation for the convection heat-transfer coefficient in totally enclosed motors as a function of the inner air velocity $v(1)$, where $k_{1}$ accounts for the natural convection and radiation of the end-windings when the motor is at standstill, and $k_{2}$ and $k_{3}$ account for the impact airflow due to the rotation of the machine in the end-space region. Selection of air velocity is not trivial, often it is assumed to be equal to the peripheral speed of the rotor. The approach in (1) is widely used nowadays.

$$
h=k_{1}\left[1+k_{2} v^{k_{3}}\right] .
$$

In [24], [25] Boglietti et al. proposed different coefficients for (1) based on experimental tests obtained for various designs with totally enclosed fan-cooled (TEFC) induction motors, as well as for an open drip proof (ODP) induction motor.

All the preceding discussion was for induction machines. Since PMSMs present relatively low rotor losses, no wafters are normally placed at the rotor ends. Considering that the moving air at the end-space is highly influenced by rotor wafters, it is evident that the heat-transfer coefficients reported for induction machines [23]-[25] cannot be applied directly to the case of PMSMs with a smooth rotor.

To the best of our knowledge, the first study of the endwinding thermal behavior for PMSMs with smooth rotors, i.e. without wafters, was released in 2017 [3]. This work studied the heat-transfer in the end-regions of an integrated starter generator using numerical CFD methods, and provided the coefficients for (1) for each surface of the end-winding cavity. However, no information is provided regarding how these coefficients should be combined (averaged) to obtain an equivalent model of the whole end-winding.
The main objective of this paper is to obtain the generalized coefficients which are required for the use of (1) with PMSMs with smooth rotors, when no specific end-winding cooling methods are employed, which comprise the majority of the electric motors employed in actual electric/hybrid vehicles [26]. Machines with internal rotor (IR) and external rotor (ER) will be considered. Furthermore, the study will include a comparative analysis between PMSMs without wafters and induction motors with wafters for completeness.

The paper is organized as follows. Section II introduces LPTN thermal models. The design of the motor prototypes used in this study is presented in Section III. Characterization of the LPTN is addressed in Section IV, characterization of the end-space heat convection, including experimental results, being presented in Section V. Finally, conclusions of this work are discussed in Section VI.

\section{Electric Machine Thermal Model}

This section describes the LPTN models. Two three-phase PMSM prototypes with IR and ER will be considered. Both machines have the same ratings.

\section{A. Basic Principles of Heat-Transfer}

LPTN models should comprise the three physical heat transfer principles: conduction, convection and radiation. Conduction is the principal heat transfer mechanism in solid materials, the thermal resistance being given by (2), where $l$ is the length across the heat propagation direction, $k$ the thermal conductivity of the material and $A$ the cross-section area perpendicular to the propagation direction.

$$
R_{\mathrm{th}_{\mathrm{cond}}}=\frac{l}{k A} \text {. }
$$

In cylindrical components the conduction thermal resistance is of the form shown in (3), where $r_{2}$ is the outer radius, $r_{1}$ the inner radius and $L$ the length of the element perpendicular to the propagation direction. $\alpha$ is the angle of the circular sector, which is $2 \pi$ for complete cylinders.

$$
R_{\mathrm{th}_{\mathrm{cond}}}=\frac{\ln \left(\frac{r_{2}}{r_{1}}\right)}{k \alpha \pi L} .
$$

Convection heat transfer occurs in fluids and gases, where particles can change their position. Convection can be natural or forced, both being modeled by (4), where $h$ is the convection heat transfer coefficient and $A$ the surface area of the element involved in the convection.

$$
R_{\mathrm{th}_{\mathrm{conv}}}=\frac{1}{h A} \text {. }
$$

Radiation is the energy emitted by any physical body because of its temperature. The equivalent thermal resistance associated with the radiation process is given by (5).

$$
R_{\mathrm{th}_{\mathrm{rad}}}=\frac{T-T_{\infty}}{\sigma \varepsilon\left(T^{4}-T_{\infty}^{4}\right) A},
$$

where $T$ is the body absolute temperature, $T_{\infty}$ the temperature of the surrounding bodies or ambient, $\sigma$ the Stefan-Boltzmann 


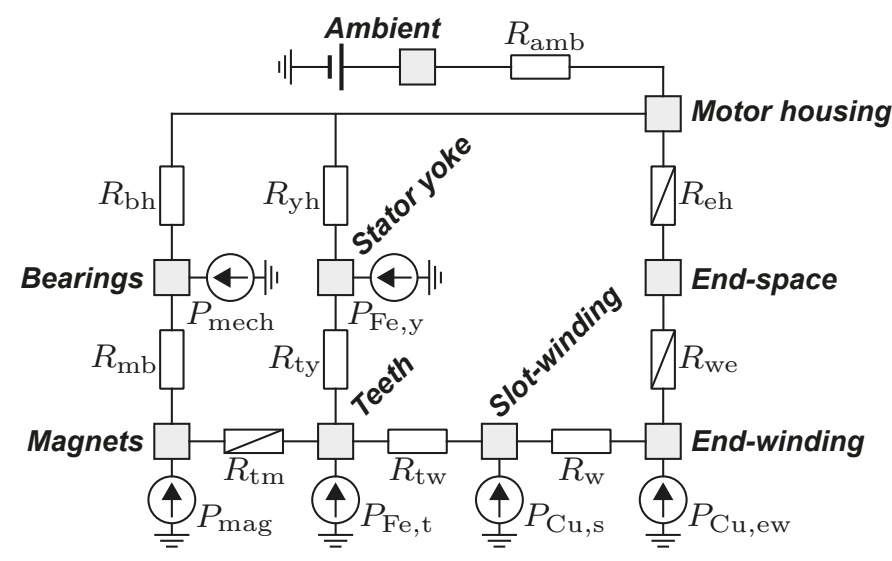

Fig. 1. Lumped-parameter thermal network of the IR motor. Resistances crossed by diagonal line indicate that the thermal path corresponds partially or totally by convection through the air (see Table I for details).

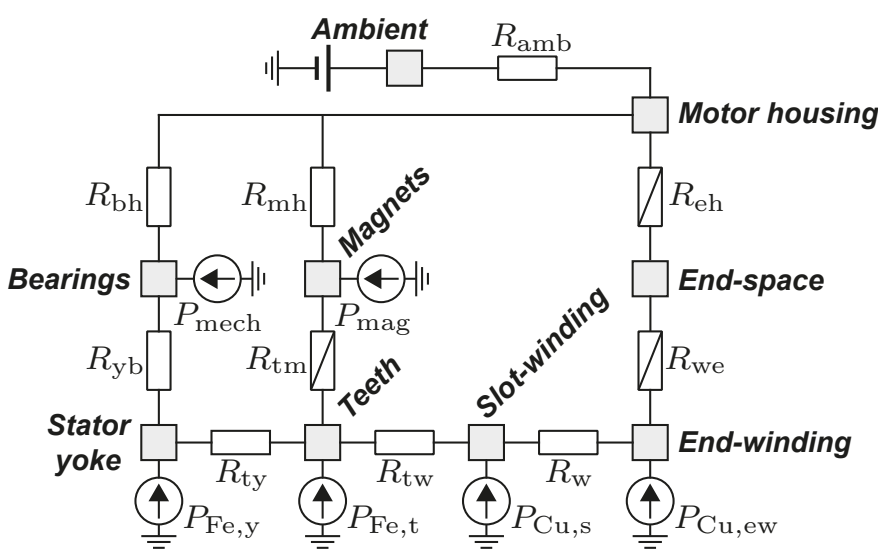

Fig. 2. Lumped-parameter thermal network of the ER motor.

constant $\left(\sigma=5.67 \cdot 10^{-8} \mathrm{~W} /\left(\mathrm{m}^{2} \mathrm{~K}^{4}\right)\right)$, $\varepsilon$ the emissivity factor of the radiative surface and $A$ its area.

\section{B. Lumped-Parameter Thermal Network}

Fig. 1 and Fig. 2 show the corresponding LPTN. In order to simplify the model, elements with similar temperatures and thermal behavior are combined in the same node, e.g., all teeth are represented by a single node, therefore average temperature of the elements are just considered. As shown in the figures, nodes being considered in the model are: motor housing, stator yoke, teeth, slot-winding, end-winding, end-space, magnets, and bearings. The model has axial symmetry, and is symmetric with respect to a horizontal containing the shaft as well. With these assumptions the LPTN is simplified considerably without compromising the accuracy of the model. Only the steady state temperatures are considered; consequently thermal capacitances are not included. Table I lists the resistances included in the models.

Stator core losses are divided into stator yoke losses $P_{\mathrm{Fe}, \mathrm{y}}$ and teeth losses $P_{\mathrm{Fe}, \mathrm{t}}$. Winding losses are split into slotwinding losses (i.e. copper inserted in the stator slots) $P_{\mathrm{Cu}, \mathrm{s}}$ and end-winding losses $P_{\mathrm{Cu} \text {,ew }}$. Copper loss distribution between slot/end-winding is estimated based on the correspond-
TABLE I

THERMAL RESISTANCES INCLUDED IN THE LPTNS

\begin{tabular}{|c|c|}
\hline $\begin{array}{l}\text { Common } \\
\text { IR and ER }\end{array}$ & Heat transfer path accounts for: \\
\hline$R_{\mathrm{amb}}$ & $\begin{array}{l}\text { Housing to ambient convection/radiation resistance } \\
{[27] /(5) \text {. }}\end{array}$ \\
\hline$R_{\mathrm{we}}$ & * End-winding convection resistance with internal air. \\
\hline$R_{\mathrm{eh}}$ & * End-cap convection resistance with the internal air. \\
\hline$R_{\mathrm{w}}$ & $\begin{array}{l}\text { Coil copper conduction resistance for the embedded } \\
\text { section (2). }\end{array}$ \\
\hline$R_{\mathrm{tw}}$ & $\begin{array}{l}\dagger \text { Equivalent resistance between coil, insulation and stator } \\
\text { teeth. }\end{array}$ \\
\hline$R_{\mathrm{tm}}$ & $\begin{array}{l}\text { - Magnet conduction resistance (half magnet height) (3). } \\
\text { - Air-gap convection resistance. [28] } \\
\text { - Stator teeth conduction resistance (half tooth height) (2). }\end{array}$ \\
\hline$R_{\mathrm{ty}}$ & $\begin{array}{l}\text { Stator teeth conduction resistance (half tooth height) (2). } \\
\text { Stator yoke conduction resistance (half yoke height) (3). }\end{array}$ \\
\hline$R_{\mathrm{bh}}$ & Bearings equivalent resistance [28]. \\
\hline $\begin{array}{l}\text { Specific IR } \\
\text { machine }\end{array}$ & Heat transfer path accounts for: \\
\hline$R_{\mathrm{yh}}$ & $\begin{array}{l}\text { - Stator yoke conduction resistance (half yoke height) (3). } \\
\dagger \text { Housing-stator yoke contact resistance. } \\
\cdot \text { Housing conduction resistance (3). }\end{array}$ \\
\hline$R_{\mathrm{mb}}$ & $\begin{array}{l}\text { Magnet conduction resistance (half magnet height) (3). } \\
\text { Rotor yoke conduction resistance (3). } \\
\text { Shaft conduction resistance (2) (3). } \\
\text { Bearings equivalent resistance. [28] }\end{array}$ \\
\hline $\begin{array}{l}\text { Specific ER } \\
\text { machine }\end{array}$ & Heat transfer path accounts for: \\
\hline$R_{\mathrm{mh}}$ & $\begin{array}{l}\cdot \text { Magnet conduction resistance (half magnet height) (3). } \\
\dagger \text { Adhesive epoxy layer between magnets and rotor. } \\
\cdot \text { Rotor yoke conduction resistance (3). } \\
\dagger \text { Housing-rotor yoke contact resistance. } \\
\cdot \text { Housing conduction resistance (3). }\end{array}$ \\
\hline$R_{\mathrm{yb}}$ & $\begin{array}{l}\text { - Stator yoke conduction resistance (half yoke height) (3). } \\
\text { - Bearings equivalent resistance. [28] } \\
\text { - Shaft conduction resistance (2) (3). }\end{array}$ \\
\hline
\end{tabular}

* Denotes heat paths involved in the end-space convection.

$\dagger$ Denotes heat paths affected by the manufacturing process.

ing volumes, with a share of $47.3 / 52.7 \%$ for the IR and $51.2 / 48.8 \%$ for the ER. The heat produced by mechanical losses $P_{\text {mech }}$ is assumed to occur in the bearings. $P_{\text {mag }}$ represents the magnet losses. As can be seen in Table I, some thermal resistances account for more than one element in the conduction/convection heat path. For each element in Table I the corresponding equation number as well as examples in the existing literature are provided. Resistances crossed by a diagonal line indicate that convection through the air is involved. The most relevant difference between the two networks is in the location of convection resistances. It is noted that air presents considerably higher thermal resistance compared to the other elements in the heat paths. In the IR motor, the stator is assembled to the motor housing, providing a relatively low thermal resistance path to ambient. On the other hand, in the ER motor, there is an air-gap layer between the stator and the rotor assembled to the housing, stator heat dissipation through this path being problematic. 


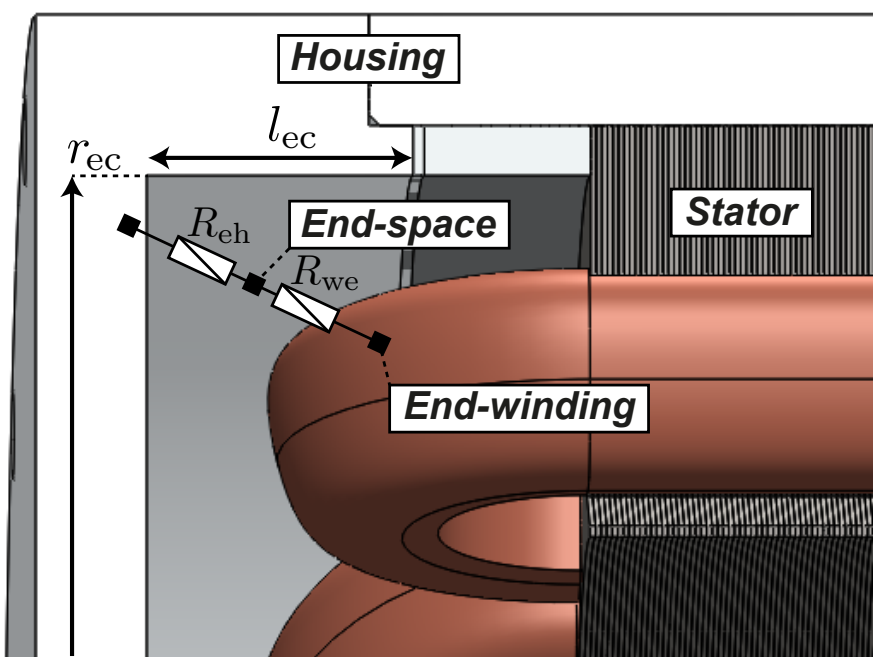

Fig. 3. Thermal resistance model for the convection heat transfer through the end-space. Details of the geometry and dimensions of the housing and end-cap involved are also shown.

While it is relatively straightforward to estimate most of the resistances included in Table I with reasonable accuracy, it can be challenging in some cases, e.g. when the heat path depend on the manufacturing process of the machine (marked with ' $\dagger$ ' in Table I), or when the heat transmission is by means of convection in the end-space (marked with ' $*$ ' in Table I). Prior to the analysis of the end-space convection, a number of experimental tests (see Section IV) had been carried out in order to precisely characterize the aforementioned thermal resistances.

\section{End-space heat convection modeling}

In the approach proposed in this paper, heat convection through the air within the machine is modeled using two thermal resistances in series between the end-windings and the housing end-cap as shown in Fig. 3. Stator and rotor iron heat convection through the end-space is neglected. The reason is that their temperature is considerably lower than that of the end-windings, meaning most of heat dissipation at the end-space will occur at the end-winding. It is also desirable to keep the LPTN as simple as possible, as adding more convection thermal resistances would considerably increase the complexity of the proposed fitting method with a very modest impact on the overall accuracy.

Surface areas to be considered include the end-winding on one side, and motor housing and end-cap on the other. Motor housing and end-cap areas can be approached as a cylinder and a disk respectively as shown in (6) (see Fig. 3 for details).

$$
A_{e c}=2\left(\pi \cdot r_{\mathrm{ec}}^{2}+2 \pi \cdot r_{\mathrm{ec}} l_{\mathrm{ec}}\right) .
$$

The reduction of the end-cap surface areas due to the rotor shaft has been neglected in (6). Also the end-cap has been modeled as a totally flat surface, while often it is slightly curved. It is noted that the two simplifications introduced in (6) have opposite effects, and therefore compensate to each other to a certain extent.

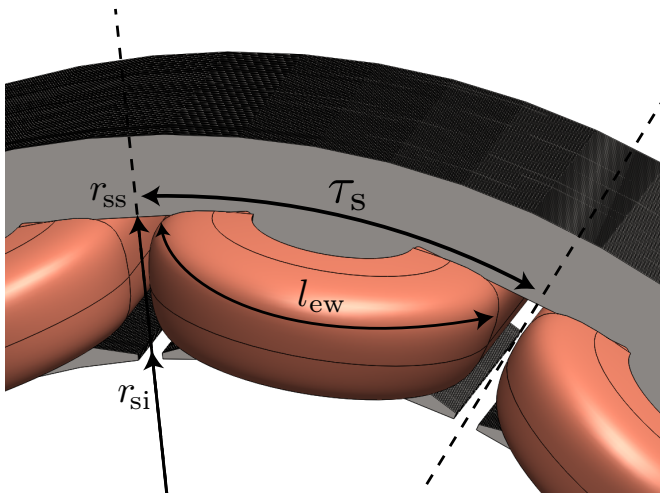

Fig. 4. Details of the geometry and dimensions of the end-winding in a FSCW.

TABLE II

FSCW PMSM DESIGN CONSTRAINTS

\begin{tabular}{l|l}
\hline Number of stator slots & 12 \\
Number of pole pairs & 5 \\
Active stack length & $50 \mathrm{~mm}$ \\
External diameter & $274 \mathrm{~mm}$ \\
Airgap height & $2 \mathrm{~mm}$ \\
Magnet arc & $85 \%$ \\
Fundamental airgap flux density peak & $1 \mathrm{~T}$ \\
Total electric load & $16.5 \mathrm{kA} / \mathrm{m}$ \\
Slot RMS current density & $3 \mathrm{~A} / \mathrm{mm}^{2}$ \\
Rated speed & $1080 \mathrm{rpm}$ \\
\hline
\end{tabular}

End-windings usually have a relatively complex geometry, getting and estimate of the effective surface area involved in the convection being more difficult. However, for a case of machines with FSCW, the problem simplifies significantly, as there is no interference among conductors of different phases or slots. In this work the end-winding surface area has been approached as (7), which takes into consideration the thickness of the coil, i.e. $r_{\mathrm{ss}}-r_{\mathrm{si}}$, and the ratio between the total length of the end-winding for the concentrated winding case $l_{\mathrm{ew}}$ and the slot pitch $\tau_{\mathrm{s}}$ (see Fig. 4).

$$
A_{\mathrm{ew}}=2 \pi\left(r_{\mathrm{ss}}^{2}-r_{\mathrm{si}}^{2}\right) \frac{l_{\mathrm{ew}}}{\tau_{\mathrm{s}}} .
$$

It is noted that both (6) and (7) are multiplied by two to account for the axial symmetry of the machine. It is finally noted that (7) is valid for the concentrated windings case shown in Fig. 5 and Fig. 6. Other end-winding geometries might require a different approach.

\section{ELECTRIC MOTOR PROTOTYPES}

Two electric motors with IR and ER have been built to validate the proposed thermal model. Both are three-phase surface-mounted PMSMs with a 10-pole/12-slot configuration and FSCW. Both machines have been sized according to design constraints shown in Table II. Design details for both prototypes affecting to end-space convection heat-transfer are shown in Table III. Further details on the designs can be found in [29]. 
TABLE III

MAIN DATA OF THE PROTOTYPES

\begin{tabular}{l|c|c} 
& IR \& ER \\
\hline External diameter (housing), [mm] & \multicolumn{2}{|c}{294} \\
External length (housing), [mm] & \multicolumn{2}{|c}{150} \\
Rotor stack length, $[\mathrm{mm}]$ & \multicolumn{2}{|c}{50} \\
End-cap radius $\left(r_{\mathrm{ec}}\right),[\mathrm{mm}]$ & \multicolumn{2}{|c}{132.5} \\
End-cap length $\left(l_{\mathrm{ec}}\right),[\mathrm{mm}]$ & \multicolumn{2}{|c}{40} \\
\hline & IR & ER \\
\hline Rated power, [kW] & 3.6 & 4.5 \\
Rotor (air-gap) radius, [mm] & 99 & 114 \\
Slot top radius $\left(r_{\mathrm{ss}}\right),[\mathrm{mm}]$ & 123.7 & 109.5 \\
Slot bottom radius $\left(r_{\mathrm{si}}\right),[\mathrm{mm}]$ & 103.5 & 69.5 \\
Slot pitch $\left(\tau_{\mathrm{s}}\right),[\mathrm{mm}]$ & 42.8 & 36.6 \\
End-winding length $\left(l_{\mathrm{ew}}\right),[\mathrm{mm}]$ & 55.7 & 47.6 \\
Number of turns/phase & 248 & 228 \\
Conductor diameter/parallel, $[\mathrm{mm}]$ & $0.5 \mathrm{x} 8$ & $0.56 \times 8$ \\
\hline
\end{tabular}
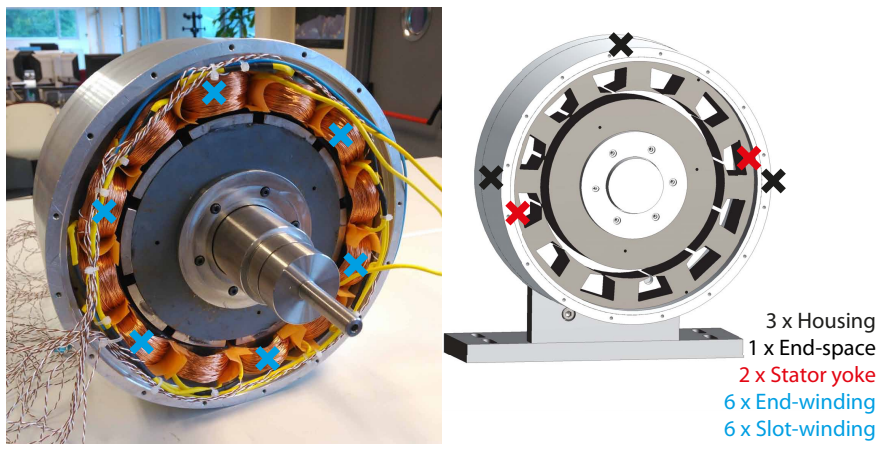

Fig. 5. IR prototype without housing end-caps and thermocouple distribution.

End-windings in FSCW designs are considerably reduced compared to standard winding configurations. A shorter endwinding implies a decrease in the phase resistance, and therefore in the copper loss, but also a reduction of the area available to dissipate heat through the internal air of the machine. Moreover, the rotors of the prototypes are smooth, in contrast to traditional industrial motors that have wafters, what reduces the air flow considerably. End-windings will therefore dissipate less heat compared to machines with standard windings and rotor wafters.

A picture of the prototypes without the housing end-caps is presented in Fig. 5 and Fig. 6 for the IR and ER, respectively. Both machines are totally enclosed by a cylindrical aluminium housing, with no wafters or additional cooling systems. Heat dissipation occurs exclusively by natural convection. However, in the case of the ER machine, where the rotor is placed in the external side of the structure, the housing rotates at the rotor speed. The cooling can be considered therefore as forced convection with an equivalent air speed equal to the peripheral speed of the machine.

Machines' temperatures were measured using several Ttype thermocouples distributed along the end-windings, slotwindings, stator yoke, housing, and end-space air. These locations correspond to nodes of the LPTN. For the particular case of the ER motor, thermocouples were also placed attached

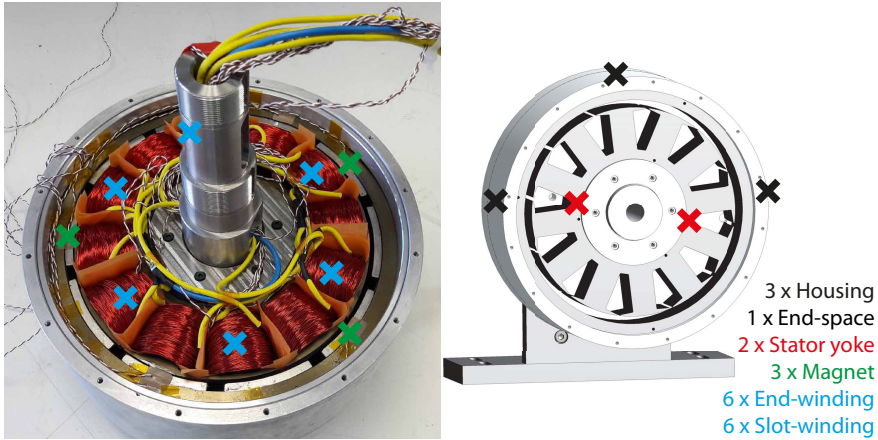

Fig. 6. ER prototype without housing end-caps and thermocouple distribution.

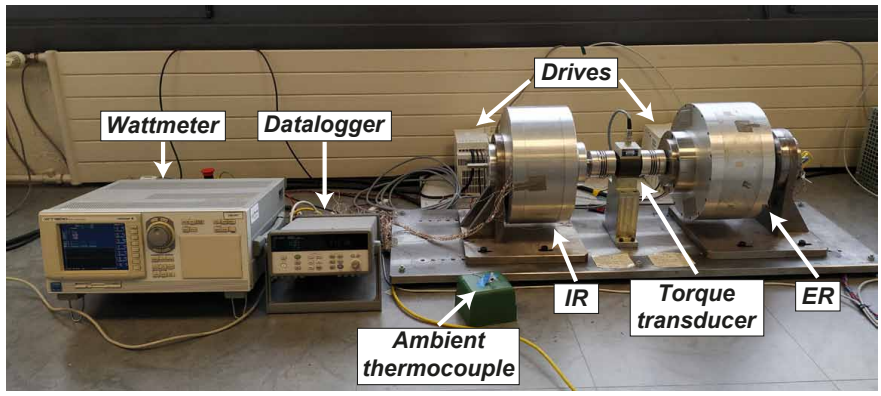

Fig. 7. Test-bench setup with both motor prototypes.

at the magnets. Thermocouples distribution is shown in Fig. 5 and Fig. 6. Acquisition was performed using an Agilent 34970A datalogger. Temperatures shown in this paper are the average value of all the measurements belonging to a LPTN node.

Both motors were connected in the test-bench in a backto-back configuration, as shown in Fig. 7. Each machine is fed by an ABB commercial drive. Torque is measured with a HBM T22 torque transducer, while all electrical variables are captured using a Yokogawa WT1600 wattmeter. All signal processing is implemented in Matlab.

\section{Lumped-Parameter Thermal Network CHARACTERIZATION}

Previous to characterizing the end-space convection heattransfer coefficients, a precise model of the other elements involved in LPTN circuits is required. The following losses sources must be measured for this purpose: Joule losses in the end-winding and slot-winding; iron losses in the stator yoke and teeth; magnet losses and mechanical losses (see Fig. 1 and Fig. 2). Thermal resistances subjected to uncertainty due to the manufacturing process (marked with ' $\dagger$ ' in Table I) must also be estimated. Once this is accomplished, the only unknown variables in the model will be the end-space related thermal resistances $R_{\mathrm{we}}$ and $R_{\mathrm{eh}}$. Three types of tests are proposed to characterize all these elements:

- DC test

- Open circuit test

- Load test 


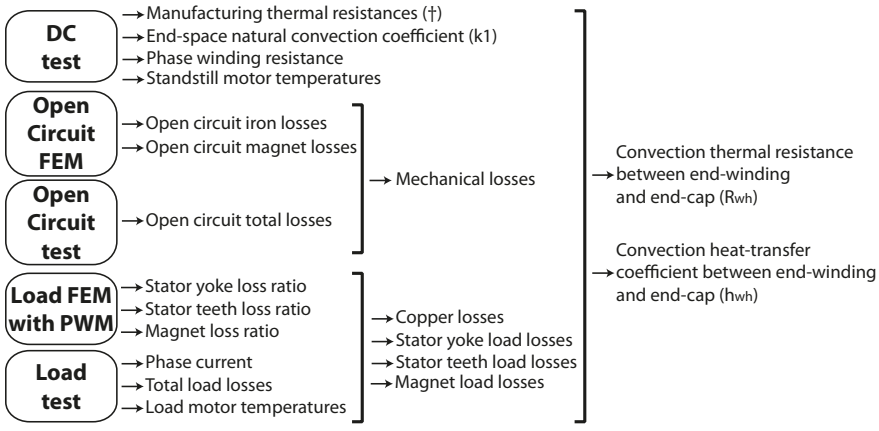

Fig. 8. Test diagram for the characterization of the end-space convection heat-transfer coefficients.

Fig. 8 summarizes the process for the characterization of the end-space convection heat-transfer coefficient. Tests details are explained in the following subsections.

\section{A. DC test}

This test applies a DC power to the stator windings, with the rotor at standstill. Power is controlled to be $80 \mathrm{~W}$ for the IR machine and $60 \mathrm{~W}$ for the ER machine. The reason for the lower power for the ER case is its reduced capability to dissipate windings heat. Power is applied until the motors reach steady-state temperature. Steady-state is assumed when the temperature increase of end-windings is lower than $0.5^{\circ} \mathrm{C}$ in an hour. The results from this test reflect the natural convection between the end-windings and the housing endcaps, which is connected to coefficient $k_{1}$ in (1).

In this test all heat is due to copper losses, what significantly simplifies LPTN analysis. Phase windings resistance can be easily and accurately measured from the applied voltage and the circulating current. Also thermal resistances which depend on the manufacturing process can be accurately calculated; these resistances are assumed to remain constant for all the tests, independent of motor speed and torque. Finally, endspace heat-transfer by means of convection when the motor is still can be characterized.

Input power and measured temperatures feed the models in Fig. 1 and Fig. 2, unknown thermal resistances marked with ' $\dagger$ ' and * in Table I being adjusted by means of nonlinear least-squares regression, implemented in MATLAB using the nlinfit function. The goal of the fitting being to minimise the error between the estimated temperatures in the models and the measured temperatures. Table IV and Table V show the temperature increase with respect to the ambient temperature, and the characterized resistances, respectively. Bearings, teeth and magnets (in the case of the IR motor) temperatures are not available and are not considered in the regression. As expected, the ER motor has higher winding temperatures even if a lower power was applied. This is explained by the fact that stator heat must dissipated through the air-gap and also the thermal resistance between the end-windings and end-caps is higher.

\section{B. Open circuit test}

The purpose of this test is to measure friction and windage losses, hereafter known as mechanical losses. Segregation of
TABLE IV

Measured Temperature InCREASE During the DC Test

\begin{tabular}{|c|c|c|c|c|c|c|}
\hline$\left[{ }^{\circ} \mathrm{C}\right]$ & Winding & $\begin{array}{c}\text { End } \\
\text { Winding }\end{array}$ & $\begin{array}{c}\text { Stator } \\
\text { Yoke }\end{array}$ & Magnet & Housing & $\begin{array}{c}\text { End } \\
\text { Space }\end{array}$ \\
\hline IR & 55.72 & 57.43 & 33.13 & - & 28.38 & 29.66 \\
\hline ER & 74.1 & 73.42 & 59.5 & 28.18 & 24.74 & 25.96 \\
\hline
\end{tabular}

TABLE V

Characterized Thermal Resistances With the DC Test

\begin{tabular}{|c|c|c|c|c|c|c|}
\hline$\left[{ }^{\circ} \mathrm{C} / \mathrm{W}\right]$ & $R_{\mathrm{tw}}$ & $R_{\mathrm{yh}}$ & $R_{\mathrm{mh}}$ & $R_{\mathrm{we}}$ & $R_{\mathrm{eh}}$ & $R_{\mathrm{we}}+R_{\mathrm{eh}}$ \\
\hline $\mathrm{IR}$ & 0.2957 & 0.0714 & - & 2.3536 & 0.1085 & 2.4621 \\
\hline $\mathrm{ER}$ & 0.2648 & - & 0.2002 & 2.8254 & 0.0726 & 2.898 \\
\hline
\end{tabular}

mechanical losses from iron and magnet losses is challenging in PMSMs, due to the impossibility of controlling the rotor flux. This problem is worsen due to the variation of losses with magnet temperature. In an open circuit test the machine is rotated externally with the stator circuit open. The overall open circuit losses are obtained from the measured torque and rotor speed. Measurements are taken once the motors reach a steady-state thermal condition. As no PWM exist, FEM can be used to obtain accurate estimations of iron and magnet losses. Mechanical losses are obtained by subtracting the iron and magnet losses estimated by FEM from the overall losses measured in the test. This process is repeated at different speeds. Fig. 9 shows the measured mechanical losses for different rotor speeds for IR and ER motors. ER motor is observed to have substantially higher losses. This was be expected due to the increased weight of the moving parts of the ER motor comparison to the IR case.

\section{Load test}

Current harmonics due to PWM are known to produce an increase of iron and magnet losses. For load tests, ER and IR machines are connected in a back-to-back configuration. ER machine worked in motoring mode while IR machine worked in generating mode. Tests at different rotor speeds

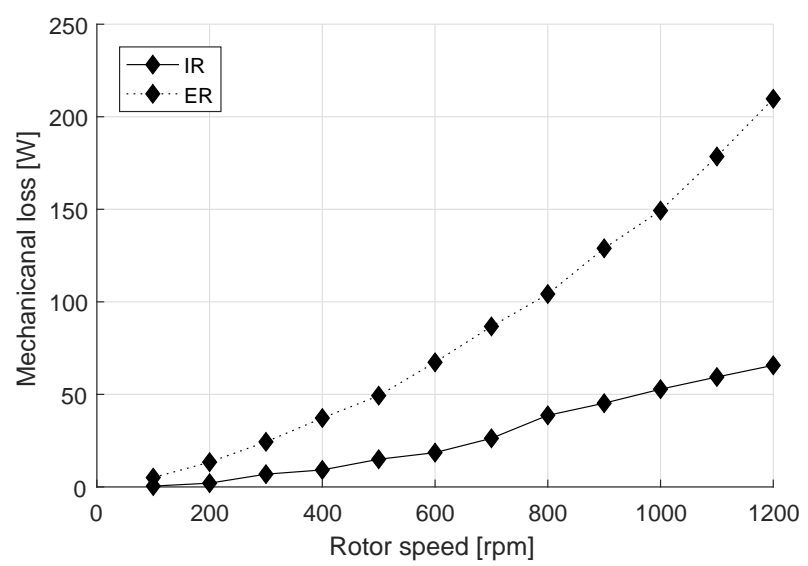

Fig. 9. Experimentally measured mechanical losses during the open circuit tests. 
were performed. Load is controlled to be constant and equal to $25 \mathrm{Nm}$. Only q-axis current is injected, current being therefore nearly constant for all the cases (minor differences can occur due to changes of mechanical losses with speed). Temperatures were monitored until the motors reached a thermal steadystate. Fig. 10 and Fig. 11 show the measured temperature increase with respect to the ambient temperature for every load test for the IR and ER motors. There is an evident rise of the temperatures with the rotor speed. This effect is seen to be less relevant for the ER motor, due to the forced convection cooling effect produced by the rotation of the rotor and external housing. The copper losses are dependent on the winding resistance, which, in turn, is dependent on the total copper length, conductor area and winding temperature; calculated values are shown in Fig. 12. No skin or proximity effect is assumed in the windings, due to the low fundamental frequency of the currents in the tested speed range. Since the mechanical and copper losses are already known, subtracting these from the total load losses, iron and magnet losses are obtained. Separation of iron and magnet losses is impossible only by empirical means; however, the ratio of iron to magnet losses can be obtained from load FEM simulations considering current harmonics due to PWM. It is possible therefore, combining experimental data and FEM, to separate iron and magnet losses. Fig. 13 shows the experimentally estimated iron and magnet losses at different rotor speeds. While for the IR motor, both the stator teeth and yoke losses values are balanced, in the case of the ER motor, the teeth losses exceeds the stator yoke losses because of the larger teeth that are employed (see Fig. 5 and Fig. 6). The magnet losses is similar for both prototypes.

It is finally noted that due to restrictions of the measurement system, temperature of rotating elements for the ER case can be only acquired with the motor is still; this applies to magnets, housing and end-space air. The time delayed due to the need to stop the motor and connect the sensors results in changes in the temperatures distribution with respect to the temperatures when the machine was rotating, especially in the internal air of the motor due to its low heat capacity. In addition, a single thermocouple inserted through a hole in the housing is used

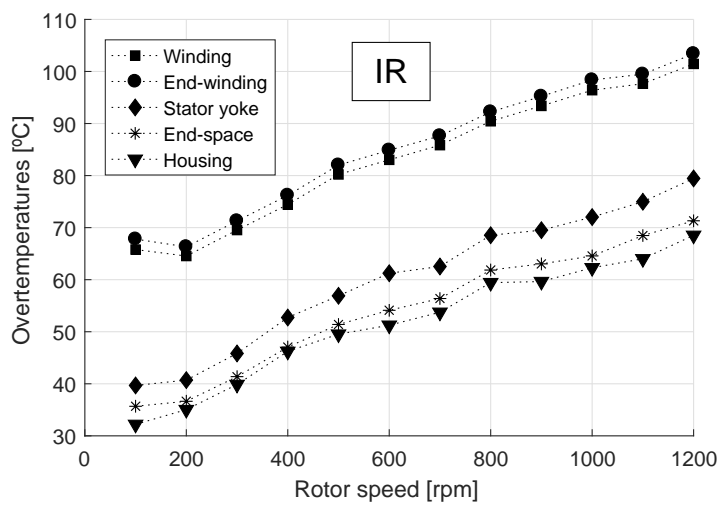

Fig. 10. Experimentally measured temperature increase during the load tests for the IR motor. For each operating condition, measurements are taken once machine has reached the steady state temperature.

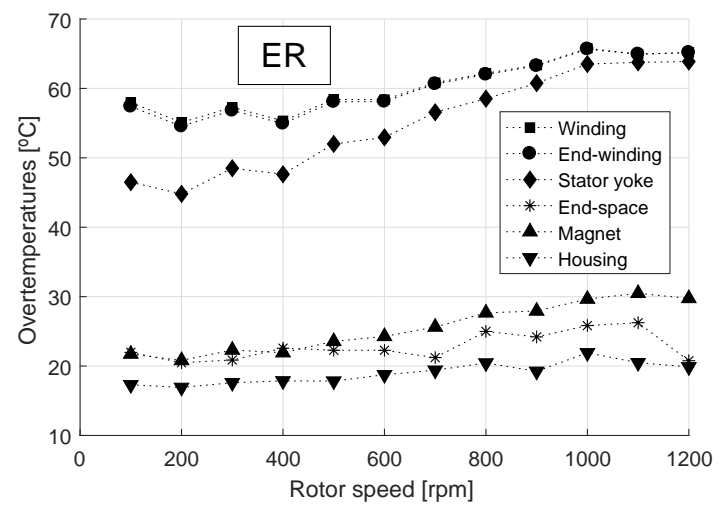

Fig. 11. Experimentally measured temperature increase during the load tests for the ER motor.

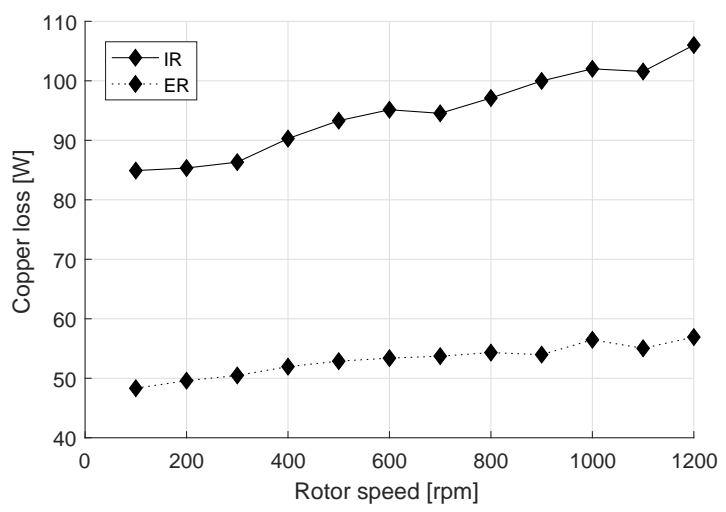

Fig. 12. Experimentally measured copper losses during the load tests.

to measure the end-space temperature. This sensor provides therefore a lumped value of distributed temperature which is expected to show significant gradients. This is believed to be the main reason for the behavior of end-space temperature for the ER motor observed in Fig. 11. However, as will be explained in Section $\mathrm{V}$, the correlation for the convection through the end-space is not affected by this issue.

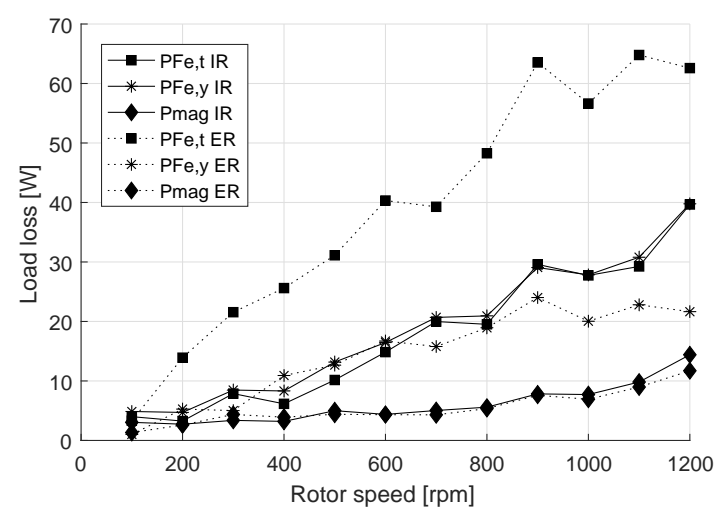

Fig. 13. Experimentally measured iron and magnet losses with included influence of PWM current harmonics. 
TABLE VI

END-SPACE THERMAL RESISTANCES FOR IR MOTOR

\begin{tabular}{|l|c|c|c|c|c|c|c|c|c|c|c|c|}
\hline \multirow{2}{*}{${ }^{\circ} \mathrm{C} / \mathrm{w}$} & \multicolumn{10}{|c|}{ Rotor speed [rpm] } \\
\cline { 2 - 14 } & 100 & 200 & 300 & 400 & 500 & 600 & 700 & 800 & 900 & 1000 & 1100 & 1200 \\
\hline$R_{\text {we }}$ & 1.80 & 2.13 & 1.82 & 1.29 & 1.39 & 1.40 & 1.35 & 1.08 & 1.10 & 1.13 & 1.00 & 0.81 \\
\hline$R_{\text {eh }}$ & 0.21 & 0.11 & 0.09 & 0.04 & 0.09 & 0.13 & 0.11 & 0.09 & 0.11 & 0.08 & 0.14 & 0.08 \\
\hline$R_{\text {wh }}$ & 2.01 & 2.24 & 1.91 & 1.33 & 1.48 & 1.53 & 1.46 & 1.17 & 1.21 & 1.21 & 1.14 & 0.89 \\
\hline
\end{tabular}

TABLE VII

End-Space Thermal Resistances for ER Motor

\begin{tabular}{|l|c|c|c|c|c|c|c|c|c|c|c|c|}
\hline \multirow{2}{*}{$\mathrm{C} / \mathrm{W}$} & \multicolumn{10}{|c|}{ Rotor speed [rpm] } \\
\cline { 2 - 14 } & 100 & 200 & 300 & 400 & 500 & 600 & 700 & 800 & 900 & 1000 & 1100 & 1200 \\
\hline$R_{\mathrm{we}}$ & 1.70 & 1.00 & 0.83 & 0.65 & 0.73 & 0.58 & 0.69 & 0.56 & 0.48 & 0.57 & 0.48 & 0.59 \\
\hline$R_{\mathrm{eh}}$ & 0.23 & 0.11 & 0.16 & 0.10 & 0.11 & 0.06 & 0.03 & 0.07 & 0.07 & 0.06 & 0.08 & 0.01 \\
\hline$R_{\mathrm{wh}}$ & 1.93 & 1.11 & 0.99 & 0.75 & 0.82 & 0.64 & 0.72 & 0.63 & 0.55 & 0.63 & 0.56 & 0.60 \\
\hline
\end{tabular}

\section{Correlations for the End-Space HEAT-TRANSFER CONVECTION COEFFICIENT ESTIMATION}

Once all the thermal resistances subjected to uncertainty due to the manufacturing process (marked with ' $\dagger$ ' in Table I) have been characterized, the steady-state temperatures during load tests measured, and the different loss sources have been estimated, the only unknown variables remaining in the LPTN are the end-space thermal resistances $R_{\mathrm{we}}$ and $R_{\mathrm{eh}}$. The overall convection heat-transfer resistance between the endwindings and the end-caps $R_{\mathrm{wh}}$ is defined as (8).

$$
R_{\mathrm{wh}}=R_{\mathrm{we}}+R_{\mathrm{eh}} .
$$

The aforementioned LPTN thermal resistances have been adjusted using again the nonlinear least-squares regression to match the measured temperatures and the estimated power losses. Results are presented in Table VI and Table VII for the IR and ER motors respectively. Even though the aforementioned expected end-space air temperature gradients measured on the ER motor will affect the estimated value of the single end-space resistances, $R_{\mathrm{we}}$ and $R_{\mathrm{eh}}$, the overall convection heat-transfer resistance (8) will not be altered.

Convection heat-transfer coefficient between the endwindings and the housing end-caps $h_{\mathrm{wh}}$ can be estimated from (4) using the approach proposed in [24]:

$$
h_{\mathrm{wh}}=\frac{1}{R_{\mathrm{wh}}}\left(\frac{1}{A_{\mathrm{ew}}}+\frac{1}{A_{\mathrm{ec}}}\right) .
$$

Fig 14 and Fig 15 show $h_{\text {wh }}$ vs. the peripheral rotor speed for the IR and ER motor respectively. The figures also show the fitted regressions according to (1). The following correlations are proposed for the estimation of the heat-transfer coefficient between the end-windings and the housing end-caps for the two machines being analyzed:

$$
\begin{gathered}
h_{\mathrm{IR}}=13.29+1.693 v . \\
h_{\mathrm{ER}}=7.968+7.234 v^{0.5795} .
\end{gathered}
$$

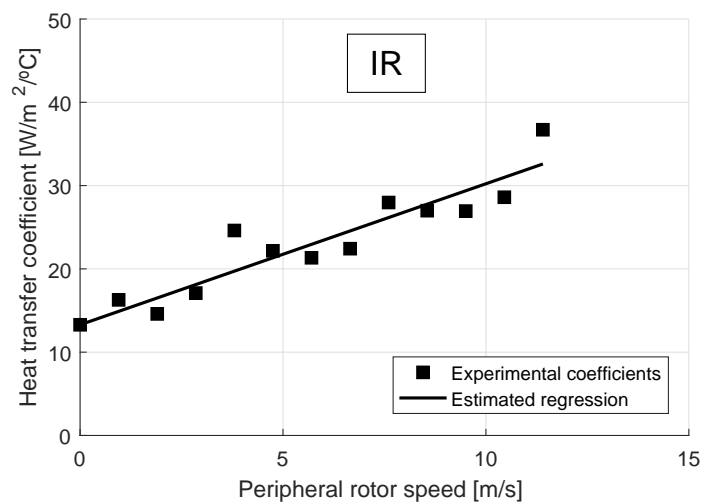

Fig. 14. Estimated convection heat-transfer coefficient between the endwindings and housing end-caps for the IR motor.

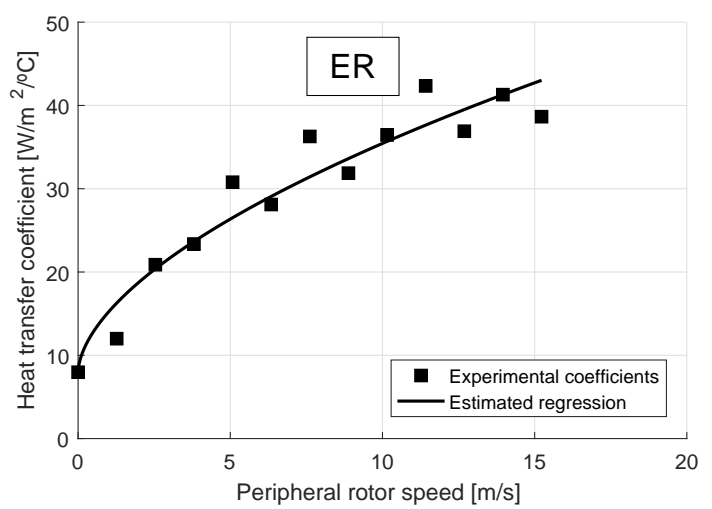

Fig. 15. Estimated convection heat-transfer coefficient between the endwindings and housing end-caps for the ER motor.

The first term in (10) and (11) accounts for the natural convection coefficient that was characterized during the DC test (see Section IV). The ER motor has a lower natural convection coefficient, which can be explained by the larger distance between the end-windings and the top face of the housing end-caps.

It is interesting to note that the correlation for the ER motor shows a knee at low peripheral rotor speeds but straightens at higher speeds, while the correlation for the IR motor shows a linear relationship for all speeds. This suggests that rotation of the outer rotor has a significant impact on the internal air flow at low speeds, but the changes when speed increases are modest due to the smooth rotor and reduced end-windings.

Applying the correlations (10) and (11) to their respective LPTN models, the errors shown in Table VIII and Table IX are obtained for the slot-winding temperature $\left(T_{\mathrm{w}}\right)$ and the end-winding temperature $\left(T_{\mathrm{ew}}\right)$.

Finally, the heat-transfer coefficients obtained using the proposed method are compared in Fig. 16 with results reported in the literature. While a similar trend is observed, the values obtained in this work are seen to be smaller than those previously reported. A reason for this is that studies in the literature were performed on induction motors having rotor wafters, for which the increase of internal air flow with peripheral rotor speed is therefore expected to be much bigger compared to the case 
TABLE VIII

IR MOtOR ESTIMATED TEMPERATURE ERROR

\begin{tabular}{|c|c|c|c|c|c|c|c|c|c|c|c|c|}
\hline \multirow{2}{*}{${ }^{\circ} \mathrm{C}$} & \multicolumn{10}{|c|}{ Rotor speed [rpm] } \\
\cline { 2 - 11 } & 100 & 200 & 300 & 400 & 500 & 600 & 700 & 800 & 900 & 1000 & 1100 & 1200 \\
\hline$T_{\mathrm{w}}$ & 0.62 & -0.73 & -0.45 & 1.55 & 0.22 & -0.31 & -0.77 & 0.62 & -0.35 & -0.84 & -0.74 & 1.22 \\
\hline$T_{\mathrm{ew}}$ & 0.66 & -0.84 & -0.64 & 1.37 & -0.06 & -0.71 & -1.22 & 0.12 & -0.99 & -1.66 & 1.53 & 0.26 \\
\hline
\end{tabular}

TABLE IX

ER MOTOR Estimated TEMPERATURE ERROR

\begin{tabular}{|l|c|c|c|c|c|c|c|c|c|c|c|c|}
\hline \multirow{2}{*}{${ }^{\circ} \mathrm{C}$} & \multicolumn{10}{|c|}{ Rotor speed [rpm] } \\
\cline { 2 - 11 } & 100 & 200 & 300 & 400 & 500 & 600 & 700 & 800 & 900 & 1000 & 1100 & 1200 \\
\hline$T_{\mathrm{w}}$ & -5.14 & -3.14 & -0.08 & 0.06 & -2.71 & 0.19 & -2.13 & -2.15 & 1.98 & -1.71 & 1.98 & -2.17 \\
\hline$T_{\mathrm{ew}}$ & -4.58 & -2.99 & -0.23 & -0.38 & -3.36 & -0.81 & -3.26 & -3.52 & 0.15 & -3.40 & -0.06 & -4.20 \\
\hline
\end{tabular}

of machine with smooth rotors. Furthermore, the motors used in these references had distributed windings, which require much larger end-windings compared to designs with FSCW. Such large end-windings normally result in reduced end-space (i.e. reduced distance between end-winding and housing endcaps), therefore increasing the heat transfer coefficient when the motor is still.

The results shown in Fig. 16 evidence the relevance of the errors in the estimated convection heat-transfer coefficients which can occur when the particularities of the motor are not properly considered during the design stage. Correlations shown in (10) and (11) for PMSMs with FSCW had not been reported before to the best of authors knowledge, and can be therefore useful for researchers requiring a fast characterization of the heat-transfer for these type of machines.

\section{CONCLUSION}

Analysis of heat-transfer in the end-space region of FSCW PMSM has been addressed in this work. Both internal rotor and external rotor designs have been considered.

A LPTN has been designed for each motor. Convection within the end-space has been modeled as series connection of thermal resistances between the end-windings and the housing end-caps. FEM and different types of tests using real prototypes have been combined to characterize the different

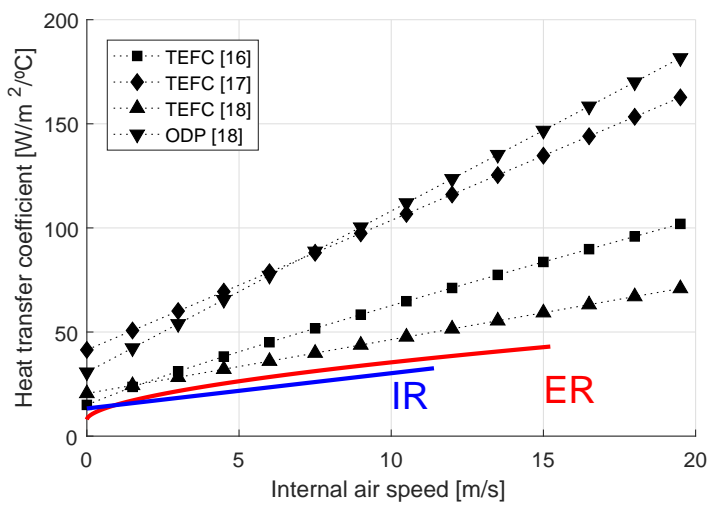

Fig. 16. Comparison of the heat-transfer coefficients obtained in this work with results reported in the literature. elements of the LPTN. Convection heat-transfer coefficient between the end-windings and the end-caps as a function of the internal air speed for each motor design has been obtained.

The results obtained in this work have been compared with those reported in the literature. Heat-transfer coefficient at stand still, as well as its increase with rotor speed has been found to be smaller than reported in the literature. This is due to the fact that published reports were for machines using conventional windings and rotor with wafters, compared to the concentrated windings and rotor without wafters used in this work. It has also been observed that there are some significant differences in the coefficients trends for the case of external and internal rotor designs, especially in the low speed region. It is finally remarked that the differences observed between the coefficients obtained in this work and those reported in the literature evidence the risks of incorrect designs if the particularities of the motor regarding convection process in the end-space are not considered.

\section{REFERENCES}

[1] A. EL-Refaie, "Fractional-Slot Concentrated-Windings Synchronous Permanent Magnet Machines: Opportunities and Challenges," IEEE Transactions on Industrial Electronics, vol. 57, no. 1, pp. 107-121, Jan. 2010.

[2] P. B. Reddy, A. M. El-Refaie, K.-K. Huh, J. K. Tangudu, and T. M. Jahns, "Comparison of Interior and Surface PM Machines Equipped With Fractional-Slot Concentrated Windings for Hybrid Traction Applications," IEEE Transactions on Energy Conversion, vol. 27, no. 3, pp. 593-602, Sep. 2012.

[3] A. B. Nachouane, A. Abdelli, G. Friedrich, and S. Vivier, "Numerical Study of Convective Heat Transfer in the End Regions of a Totally Enclosed Permanent Magnet Synchronous Machine," IEEE Transactions on Industry Applications, vol. 53, no. 4, pp. 3538-3547, Jul. 2017.

[4] C. J. Ifedi, B. C. Mecrow, S. T. M. Brockway, G. S. Boast, G. J. Atkinson, and D. Kostic-Perovic, "Fault-Tolerant In-Wheel Motor Topologies for High-Performance Electric Vehicles," IEEE Transactions on Industry Applications, vol. 49, no. 3, pp. 1249-1257, May. 2013.

[5] S.-U. Chung, S.-H. Moon, D.-J. Kim, and J.-M. Kim, "Development of a 20-Pole-24-Slot SPMSM With Consequent Pole Rotor for In-Wheel Direct Drive," IEEE Transactions on Industrial Electronics, vol. 63, no. 11, pp. 7144-7144, Nov. 2016.

[6] R. Wrobel, P. H. Mellor, N. McNeill, and D. A. Staton, "Thermal Performance of an Open-Slot Modular-Wound Machine With External Rotor," IEEE Transactions on Energy Conversion, vol. 25, no. 2, pp. 403-411, Jun. 2010.

[7] Y. Yang, M. M. Rahman, T. Lambert, B. Bilgin, and A. Emadi, "Development of an External Rotor V-Shape Permanent Magnet Machine for E-Bike Application," IEEE Transactions on Energy Conversion, vol. 33, no. 4, pp. 1650-1658, Dec. 2018.

[8] H. Surong, L. Jian, F. Leonardi, and T. Lipo, "A General Approach to Sizing and Power Density Equations for Comparison of Electrical Machines," IEEE Transactions on Industry Applications, vol. 34, no. 1, pp. 92-97, 1998.

[9] A. Boglietti, A. Cavagnino, D. Staton, M. Shanel, M. Mueller, and C. Mejuto, "Evolution and Modern Approaches for Thermal Analysis of Electrical Machines," IEEE Transactions on Industrial Electronics, vol. 56, no. 3, pp. 871-882, Mar. 2009.

[10] P. Mellor, D. Roberts, and D. Turner, "Lumped Parameter Thermal Model for Electrical Machines of TEFC Design," IEE Proceedings $B$ Electric Power Applications, vol. 138, no. 5, p. 205, 1991.

[11] O. Wallscheid and J. Bocker, "Global Identification of a Low-Order Lumped-Parameter Thermal Network for Permanent Magnet Synchronous Motors," IEEE Transactions on Energy Conversion, vol. 31, no. 1, pp. 354-365, Mar. 2016.

[12] C. Jungreuthmayer, T. Bauml, O. Winter, M. Ganchev, H. Kapeller, A. Haumer, and C. Kral, "A Detailed Heat and Fluid Flow Analysis of an Internal Permanent Magnet Synchronous Machine by Means of Computational Fluid Dynamics," IEEE Transactions on Industrial Electronics, vol. 59, no. 12, pp. 4568-4578, Dec. 2012. 
[13] M. Satrústegui, G. Artetxe, I. Elosegui, M. Martinez-Iturralde, and J. C. Ramos, "Wafter Design for Totally Enclosed Electric Machines," Applied Thermal Engineering, vol. 129, pp. 93-105, 2018.

[14] C. Micallef, S. J. Pickering, K. A. Simmons, and K. J. Bradley, "Improved Cooling in the End Region of a Strip-Wound Totally Enclosed Fan-Cooled Induction Electric Machine," IEEE Transactions on Industrial Electronics, vol. 55, no. 10, pp. 3517-3524, Oct. 2008.

[15] J.-F. Trigeol, Y. Bertin, and P. Lagonotte, "Thermal Modeling of an Induction Machine Through the Association of Two Numerical Approaches," IEEE Transactions on Energy Conversion, vol. 21, no. 2, pp. 314-323, Jun. 2006.

[16] M. Hettegger, B. Streibl, O. Biro, and H. Neudorfer, "Measurements and Simulations of the Convective Heat Transfer Coefficients on the End Windings of an Electrical Machine," IEEE Transactions on Industrial Electronics, vol. 59, no. 5, pp. 2299-2308, May. 2012.

[17] S. Nategh, Z. Huang, A. Krings, O. Wallmark, and M. Leksell, "Thermal Modeling of Directly Cooled Electric Machines Using Lumped Parameter and Limited CFD Analysis," IEEE Transactions on Energy Conversion, vol. 28, no. 4, pp. 979-990, Dec. 2013.

[18] D. Staton, A. Boglietti, and A. Cavagnino, "Solving the More Difficult Aspects of Electric Motor Thermal Analysis in Small and Medium Size Industrial Induction Motors," IEEE Transactions on Energy Conversion, vol. 20, no. 3, pp. 620-628, Sep. 2005.

[19] A. J. Grobler, S. R. Holm, and G. van Schoor, "Empirical Parameter Identification for a Hybrid Thermal Model of a High-Speed Permanent Magnet Synchronous Machine," IEEE Transactions on Industrial Electronics, vol. 65, no. 2, pp. 1616-1625, Feb. 2018.

[20] H. Vansompel, A. Yarantseva, P. Sergeant, and G. Crevecoeur, "An Inverse Thermal Modeling Approach for Thermal Parameter and Loss Identification in an Axial Flux Permanent Magnet Machine," IEEE Transactions on Industrial Electronics, vol. 66, no. 3, pp. 1727-1734, Mar. 2019.

[21] R. Camilleri, P. Beard, D. A. Howey, and M. D. McCulloch, "Prediction and Measurement of the Heat Transfer Coefficient in a Direct OilCooled Electrical Machine With Segmented Stator," IEEE Transactions on Industrial Electronics, vol. 65, no. 1, pp. 94-102, Jan. 2018

[22] V. Madonna, A. Walker, P. Giangrande, G. Serra, C. Gerada, and M. Galea, "Improved Thermal Management and Analysis for Stator End-Windings of Electrical Machines," IEEE Transactions on Industrial Electronics, vol. 66, no. 7, pp. 5057-5069, Jul. 2019.

[23] E. Schubert, "Heat Transfer Coefficients at End Winding and Bearing Covers of Enclosed Asynchronous Machines," Elektrie, vol. 22, pp. 160$162,1968$.

[24] A. Boglietti and A. Cavagnino, "Analysis of the Endwinding Cooling Effects in TEFC Induction Motors," IEEE Transactions on Industry Applications, vol. 43, no. 5, pp. 1214-1222, 2007.

[25] A. Boglietti, A. Cavagnino, D. A. Staton, M. Popescu, C. Cossar, and M. I. McGilp, "End Space Heat Transfer Coefficient Determination for Different Induction Motor Enclosure Types," IEEE Transactions on Industry Applications, vol. 45, no. 3, pp. 929-937, 2009.

[26] E. A. Grunditz and T. Thiringer, "Performance Analysis of Current BEVs Based on a Comprehensive Review of Specifications," IEEE Transactions on Transportation Electrification, vol. 2, no. 3, pp. 270289, Sep. 2016

[27] D. A. Staton and A. Cavagnino, "Convection Heat Transfer and Flow Calculations Suitable for Electric Machines Thermal Models," IEEE Transactions on Industrial Electronics, vol. 55, no. 10, pp. 3509-3516, Oct. 2008.

[28] G. Kylander, "Thermal Modelling of Small Cage Induction Motors," Ph.D. dissertation, Chalmers University of Technology, 1995.

[29] A. Tovar-Barranco, F. Briz, A. Lopez-de Heredia, and I. Villar, "Comparison of Permanent Magnet Synchronous Machines With Concentrated Windings and Different Rotor Configurations," in 2017 19th European Conference on Power Electronics and Applications (EPE'17 ECCE Europe), pp. P.1-P.8, Sep. 2017.

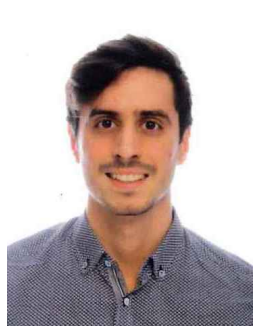

Aitor Tovar-Barranco Aitor Tovar-Barranco received the B.Sc. and M.Sc. degrees in Electronics from the University of Mondragón, Mondragón, Spain, in 2013 and 2015, respectively. $\mathrm{He}$ is currently working towards Ph.D degree in the University of Oviedo, Gijón, Spain. His research interests include the design of electric motors for traction and automotive applications, and thermal modeling of electric motors.

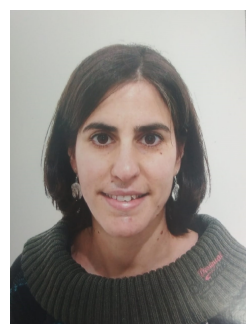

Amaia López-de-Heredia Amaia López-deHeredia received the B.Sc. degree in Electronics from the University of Mondragón (Mondragón Spain) in 2001 and the M.Sc. and Ph.D degrees from the National Polytechnic Institute of Grenoble (Grenoble, France) in 2003 and 2006, respectively. Since 2006, she has been a Researcher and Project Manager with Ikerlan Technology Research Centre, Basque Research and Technology Alliance (BRTA), Mondragón, Spain, in the power electronics area in severa industrial and research projects related to power conversion systems for railway traction, electric vehicle and renewable energies. Her research interests include modeling and advanced control of power converters and electrical machines.

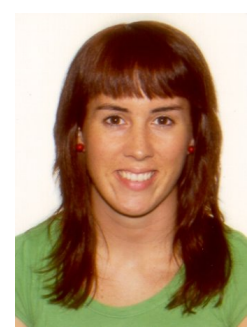

Irma Villar Irma Villar received the B.Sc. and M.Sc. degrees in Electronics from the University of Mondragón, Mondragón, Spain, in 2003 and 2005, respectively, and the Ph.D. degree in power electronics from the Federal Institute of Technology Lausanne (EPFL), Switzerland, in 2010. Since 2009, she has been a Researcher and Project Manager with Ikerlan Technology Research Centre, Basque Research and Technology Alliance (BRTA), Mondragón, Spain, in the power electronics area in several industrial and research projects related to power conversion systems for railway traction, electric vehicle, household applications, and aeronautics. Her fields of experience are the design of electromagnetic devices like transformers, inductors, and inductive transfer and heating systems.

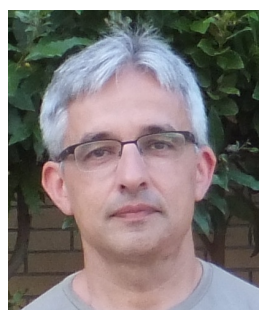

Fernando Briz Fernando Briz (A'96-M'99-SM'06) received the M.S. and Ph.D. degrees from the University of Oviedo, Gijón, Spain, in 1990 and 1996, respectively. $\mathrm{He}$ is currently a Full Professor with the Department of Electrical, Computer and Systems Engineering, University of Oviedo. His topics of interest include electronic power converters and AC drives, power systems, machine monitoring and diagnostics, and digital signal processing. Dr. Briz received an IEEE TRANSACTIONS ON INDUSTRY APPLICATIONS Award and nine IEEE Industry Applications Society Conference and IEEE Energy Conversion Congress and Exposition prize paper awards. He is past chair of the Industrial Drives Committee and current Vice-Chair of the Industrial Power Conversion System Department of the IAS. 